\title{
Study of the influence of disintegrated biomass of chlorella sorokiniana on the state of yeast saccharomyces cerevisiae
}

\author{
Tatiana Kuznetsova ${ }^{1, *}$, Olga Ivanchenko ${ }^{1}$ Anastasia Kiseleva ${ }^{1}$ and Thao Le Huong ${ }^{2}$ \\ ${ }^{1}$ Peter the Great St. Petersburg Polytechnic University, St. Petersburg, Russian Federation \\ ${ }^{2}$ Viet Tri University of Industry, 97QXF6 Tiên Kiên, Lâm Thao District, Phu Tho Province, Vietnam
}

\begin{abstract}
The physiological state of Saccharomyces cerevisiae yeast used in fermentation plants is strongly influenced by various stress factors, "stimulants" and top dressing. Effective yeast activation reduces the time it takes to prepare the finished product and increase its quality. Chlorella sorokiniana is a fast-growing microalgae, its biomass is a promising source of protein, carbohydrates, antioxidants, vitamins, magnesium and other components. Its cells have a powerful cell membrane, so the necessary step is the disintegration of the microalgae biomass. Ultrasonic, microwave disintegration methods, as well as mechanical using a high-speed homogenizer were used. When introducing disintegrated biomass at a concentration of $20 \mathrm{mg} \%$, the most effective option compared to the control (without additives) was the use of microwave disintegration: an increase in ethanol-forming ability (by 43.5\%), a visible degree of fermentation (by 39.2\%), and yeast concentration cells in the population (by 31.0\%). Ultrasonic and mechanical disintegration of microalgae biomass is less effective. Thus, the use of Chlorella sorokiniana microalgae as a source of valuable components is a promising way of activating the Saccharomyces cerevisiae yeast, which requires additional research in the development of technology for preliminary disintegration and complex processing of introduced biomass.
\end{abstract}

\section{Introduction}

Increasing the effectiveness of technological processes in industrial fermentation as well as improving the quality of finished products is an important question to cover. Its solution is associated with the growth of Saccharomycetes metabolic activity. Chemical processes in the yeast cell are easy to regulate. Relevant preparations are those that stimulate cell growth and replication, contribute in cell activity growth, improve nutrients transport, help the total fermentation of extractive substances to proceed, increase stress resistance, including high spirit concentration condition, low temperatures, yeast toxins etc [1].

The majority of yeast top-dressings allowed in Russian Federation are produced abroad. They consist of synthetic vitamins and mineral components in the form of chemical salts. Alongside vitamins, various stimulators made from plant based primary products (including aquatic organisms) are used, animal based primary products are used less often [3]. Equally important is the use of environmentally friendly drugs for food

newest cell envelope disintegration technologies. production [4].

Recently, the ways to use Spirulina platensis as a yeast activator were suggested $[5,6]$. Yeast activation is done by adding spirulina to the substratum or to the exponential growth phase go yeast in dry crushed form in aqueous suspension. The increase in fermentative activity especially in complex of hydrolytic enzymes is shown.

Cell envelope of Spirulina platensis is easy to break by using hydrolytic enzymes in contrast to cell envelopes of eukaryotic organisms like Chlorella [5].

The issue of microalgal valuable components accessibility could be solved by preliminary disintegration of cell wall in various ways [6], the most common ways to do so are mechanical methods of the most widely used mechanical methods based on the effect of shear forces of a solid (bead mill, high-speed homogenizer) [7] or shear forces of a liquid (homogenization under pressure, microfluidization) [8]; also during ultrasonic processing [10] and under the cation of electromagnetic radiation in the centimeter range (microwave) [11, 12]. The most perspective techniques are enzymatic cell degradation done in different ways and the osmotic stress. These interactions do not fully break cell envelope, but they cause its perforation and increase its permeability [12]. Explosive decompression using $\mathrm{CO}_{2}$ [13], laser processing and pulsed electric discharge [14] are known to be the

C. sorokiniana is a perspective, rapidly growing in bioreactors kind. Its dry biomass consists of about $40 \%$ proteins, $30-38 \%$ carbohydrates, $18-22 \%$ lipids [15]. The biggest area of interest are antioxidants like chlorophyll (3.5\% from dry biomass) [16]; carotenoids which are about $0.69 \%$ from dry weight [15]. Chlorella's proteins

\footnotetext{
* Corresponding author: kuznetsova.ta1@spbstu.ru
} 
contain all the essential amino acids, which are needed for the yeast growth. In $1 \mathrm{~g}$ of microalga dry biomass vitamins B1- 2-18, B2 - 21-28, B6 - 9, C - 1300-1500, $\mathrm{K}-6$, PP - 110-180, E - 10-350 are found as well as pantothenic acid - 12-17, folic acid - 485, biotin - 0.1 , leucovorin - 22 mcg $[17,18]$.

Chlorella's biomass is also rich with chlorophyll which porphyrin group contains magnesium ions. Magnesium is essential for both energetic and constructive metabolism of yeast, since it is a cofactor of many enzymes (hexokinase, glucose phosphatisomerase, peruvate phosphokinase, phosphotransferase etc) and an activator of glycolysis. Magnesium is also an activator of pyruvate decarboxylase and is essential for ethanol fermentation. [20]. Magnesium ions are involved in many metabolic processes and increase the efficiency of fermentation [21].

The aim of this work is to study the effect of the biomass of the Chlorella sorokiniana micro algae, which underwent various methods of disintegration, on the yeast activity during the main fermentation.

\section{Methods}

For the study, air-dried biomass which was obtained by cultivating the pre-culture of $C$. sorokiniana (strain 2118k) [18, 19, 22], dry baking yeast Saccharomyces cerevisiae (produced by SAF-NEVA LLC, Saint Petersburg) were used. In used air-dry biomass of $C$. sorokiniana, the moisture content did not exceed $2.5 \%$ [23].

1. To prepare the liquid suspension the biomass was preliminary subjected to mechanical homogenization, filled with water and subjected to various methods of disintegration; the mechanical method includes grinding the biomass using high-speed Silent Crusher M homogenizer (IKA ${ }^{\circledR}$ Werke, T25 Basic) at 10000 rpm for 2 mins; the ultrasonic method includes exposing the suspension of chlorella biomass to ultrasound (40 $\mathrm{kHz}$ for 30 minutes at $45^{\circ} \mathrm{C}$ ) on a WUC-A01H DAIHAN device [25]; finally, microwave disintegration included exposing the chlorella biomass to the microwave (with a frequency of $2.450 \mathrm{MHz}$ for 5 minutes) while the temperature exceeded $100{ }^{\circ} \mathrm{C}$ (microwave oven BBK 17MWS-781M / W). In the controlled sample there was no addition of chlorella biomass.

2. The prepared aqueous suspension with chlorella biomass was used as an additional component of the nutrient medium at the stage of adding a pure yeast culture. As a nutrient medium, kvass wort was used (density $1.0301 \mathrm{~g} / \mathrm{ml}$, extractivity $8.5 \%$ ), with a sugar content of $6 \mathrm{~g} \mathrm{/} 100 \mathrm{ml}$. $10 \mathrm{ml}$ of suspension with a content of $20 \mathrm{mg}$ of chlorella biomass was added per 100 $\mathrm{ml}$ of kvass wort. The mass of the added lyophilized yeast is $0.1 \mathrm{~g} / 100 \mathrm{ml}$ of culture medium.

3. Fermentation was carried out in a thermostat for 6 hours at $\mathrm{T} 32^{\circ} \mathrm{C}$. The ethanol content and the apparent degree of fermentation were determined using the Kolos2 analyzer. The concentration of yeast cells in suspension was determined by the conventional method using a Goryaev chamber [25].

4. The morpho-physiological characteristics of yeast cells were determined by analyzing intravital preparations using a Mikmed-5 microscope, microphotographs were taken using an IS-500 digital video camera, and microscopic objects were analyzed and measured using the Levengik computer program. For morphophysiological analysis of yeast cells in a population, they were ranked as: "basic", replicated (more rounded in shape); "Young" cells, which have reached the main projection area, but had a more elongated shape. The volume and area of yeast cells were found using the ellipsoid formulas; for this, the long and short axis of the cells were found [26, 27]. The number of cells measured in the population in each group is 50 .

\section{Results and Discussion}

The main indicators of fermentation are the intensity of the fermentation of the wort and the amount of carbon dioxide formed. The fermentation activity of yeast depends on their physiological state, their strain characteristics, ethanol-forming ability and the nutritional value of yeast.

As our studies have shown, the most intense ethanol formation is observed in the sample with the addition of chlorella biomass subjected to microwave and mechanical disintegration. The ethanol content exceeds the control by an average of 43.45 and $5.17 \%$, (Fig. 1).

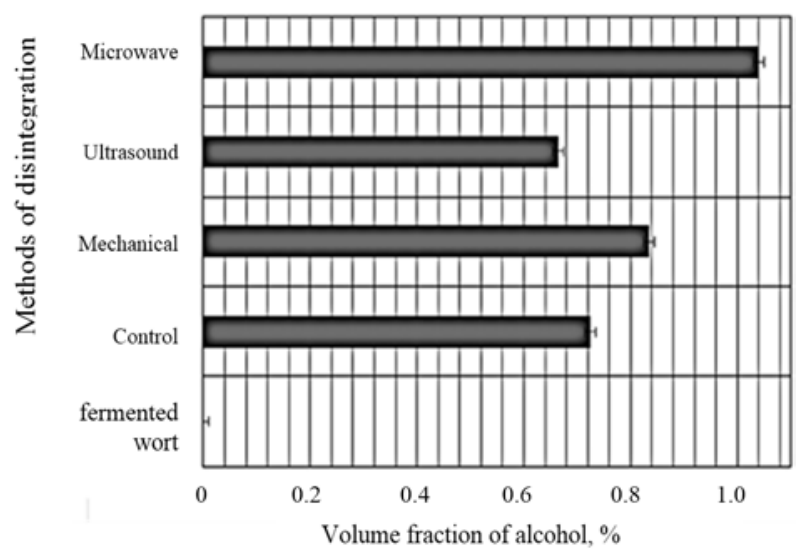

Fig. 1. Ethanol-forming ability of yeast under the influence of C. sorokiniana biomass subjected to various methods of disintegration: mechanical disintegration with a high speed homogenizer, ultrasound, microwave.

The apparent degree of fermentation is an indicator determined by the ratio of the visible extract of the fermentation drink to the extractivity of the initial wort, expressed as a percentage. This indicator also increases relative to the control sample most significantly (by $39.2 \%$ ) in the variant using biomass of $C$. sorokiniana subjected to microwave disintegration (fig. 2.). 


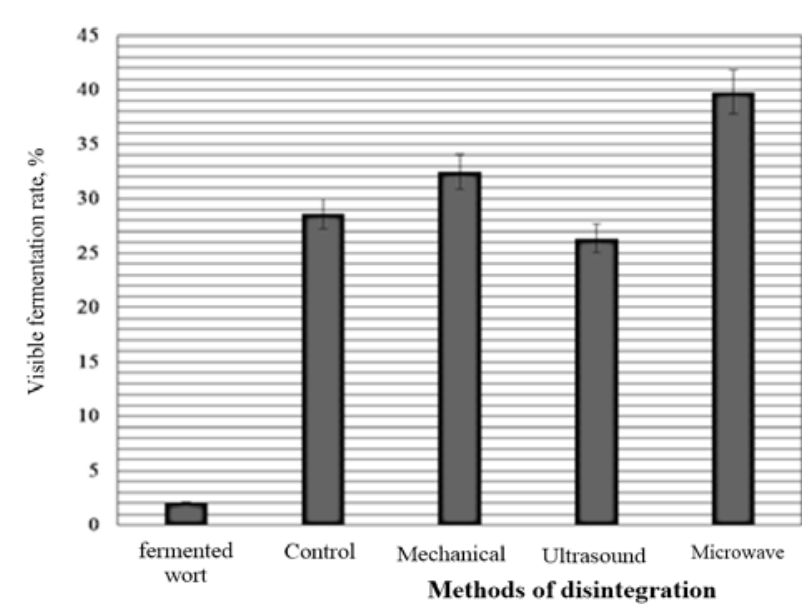

Fig. 2. The apparent degree of fermentation (\%) of kvass wort with yeast under the influence of C. sorokiniana biomass, disintegrated in different ways: mechanical disintegration with a high-speed homogenizer, ultrasound, microwave.

According to the data obtained (Table 1), the addition of chlorella biomass contributes to the intensification of yeast cell division in the variant with microwave biomass disintegration. The maximum number of cells at the end of fermentation in the sample with the addition of chlorella biomass exposed to microwave exposure is $31 \%$ higher than the control. A positive effect on the accumulation of yeast biomass of the addition of Chlorella microalgae (at a concentration of $20 \mathrm{mg} \%$ ) was noted in similar studies [18], however, pretreatment of biomass in this study enhances the effect.

Table 1. Concentration of yeast cell in a suspension at the end of fermentation, $\times 10^{6}$ cells $/ \mathrm{ml}$.

\begin{tabular}{|c|c|c|c|c|}
\hline \multirow{2}{*}{$\begin{array}{l}\text { Indi- } \\
\text { cator }\end{array}$} & Control & \multicolumn{3}{|c|}{ Methods of disintegration } \\
\cline { 3 - 5 } & & Mechanical & Ultrasound & Microwave \\
\hline $\mathrm{x} \pm \mathrm{Sx}$ & $21.53 \pm 1.51$ & $22.71 \pm 1.59$ & $24.20 \pm 1.70$ & $28.20 \pm 1.98^{*}$ \\
\hline
\end{tabular}

It is known that the size and shape of cells of the same strain can vary within certain limits depending on the cultivation conditions. The accumulation of nutrients and enzymes, the doubling of DNA occurs at the interphase, the budding occurs when the mother cell reaches a critical size.

After the bud is separated, a scar forms in the maternal cell - a daughter scar. Replicative aging is accompanied by a thickening of the cell wall, the cell acquires a rounded shape in contrast to young cells with a more elongated shape [19, 23].

The most informative morphophysiological indicators of yeast cells is the ratio of the cell surface area to its volume (Fig. 3). Replicative aging is accompanied by a decrease in this indicator. Figure 3 shows the values of the shape factor for yeast populations in variants with the addition of $C$. sorokiniana biomass subjected to various methods of disintegration. The indicator was found for two age groups in each population: for young and main cells.

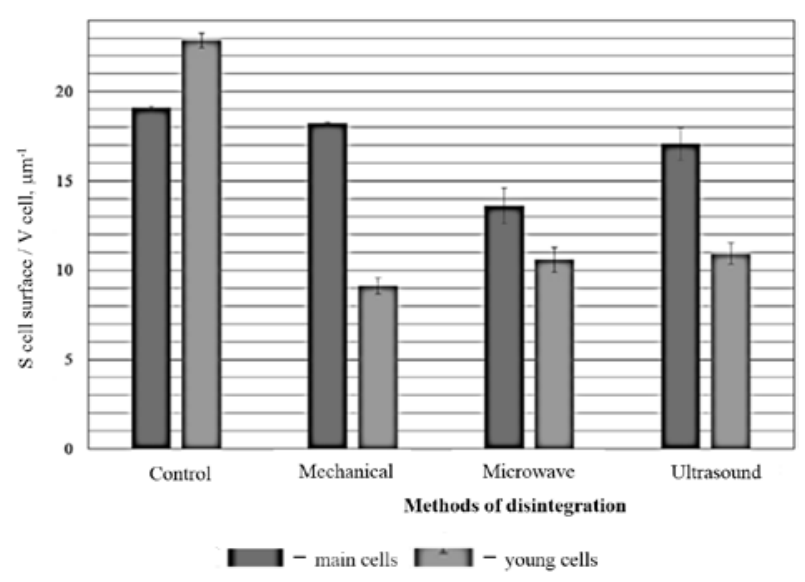

Fig. 3. The ratio of surface area to volume of age-ranked yeast cells under the influence of $C$. sorokiniana biomass subjected to different methods of disintegration: mechanical disintegration with a high-speed homogenizer, ultrasound, microwave.

The ratio of the surface area to its volume with the addition of chlorella biomass tends to decrease, the most significant decrease is observed in the case where the biomass was subjected to microwave disintegration. The intensification of budding leads to rapid replicative aging of cells in the population, which is associated with a change in the shape of the cells.

\section{Conclusions}

Chlorella sorokiniana biomass (at a concentration of 20 mg per $100 \mathrm{ml}$ of culture medium), previously subjected to microwave desintegration, increases the fermentation activity of yeast. At the same time, the ethanol-forming ability of the yeast and the visible degree of fermentation, the intensity of budding, increase. Ultrasonic and mechanical disintegration of microalgae biomass is less effective for activating $S$. cerevisiae.

Since the problem of regulating the metabolic processes of yeast in fermentation plants remains relevant, it remains relevant to search for cheap, effective natural preparations that can intensify fermentation processes and improve the quality of finished products. The use of microalgae is associated with solving the problem of increasing the bioavailability of valuable components from them and using them as stimulators of the vital activity of yeast [28].

\section{References}

1. L. V. Permyakova, in Technique and technology of food production. 3(42), (2016), pp. 46-55

2. B. R. Gibson, S. J. Lawrence, Jessica P. R. Leclaire, Chris D. Powell2 \& Katherine A. Smart, in FEMS Microbiol Rev. 31, pp. 535-569 (2007)

3. L. V. Permyakova, in the collection: Innovations in food biotechnology Proceedings of the International Symposium (Under the general editorship of A.Yu. Prosekov, 2018), pp. 486-489 
4. N.I. Didenko, D.F. Skripnuk, O.V. Mirolyubova in IOP Conference Series: Earth and Environmental Science. 72(1), (2017), pp. 1-8

5. M. V. Gernet, V. L. Lavrova, A. D. Korneev, M. Ya. Lyamin, S. I. Zaitsev, L. V. Kuznetsova, A. A. Ivanov, V. V. Vorobeva RF patent No. 2145351 C1. 02/10/2000

6. N.M. Zhuravleva, A.S. Reznik, D.V. Kiesewetter, A.M. Stolpner, E.G. Smirnova, in Proceedings of the 2019 IEEE Conference of Russian Young Researchers in Electrical and Electronic Engineering, ElConRus, (2019), pp. 838-842

7. D. R. Safina, M. N. Halimov, F. R. Tursunov, O.A. Reschetnik in International Journal of Applied Sciences and Technologies "Integral". 1. (2019), pp. 94-119

8. Y. Ma, Z. Gao, Q. Wang, Y. Liu, in Bioresour Technol. 263, (2018), pp. 631-641.

9. V. Abrahamsson, L. P. Cunico, N. Andersson, B. Nilsson, Ch. Turner in The Journal of Supercritical Fluids. 139, (2018), pp. 53-61.

10. D. P. Jaeschke, R. Rech, L. D. F. Marczak, G. D. Mercali in Bioresource Technology. 224, (2017), pp. 753-757.

11. D. Patras, C. V. Moraru, C. Socaciu in Studia UBB chemia, 1(LXIII), (2018), pp. 21-35.

12. N. Politaeva, Yu. Smyatskaya, A. Toumi in IOP Conference Series: Earth and Environmental Science, 272(3), (2019), 032056 doi:10.1088/1755$1315 / 272 / 3 / 032056$

13. L. Chronopoulou, C. D. Bosco, F. Di Caprio, L. Prosini, A. Gentili, F. Pagnanelli and C. Palocci in Molecules. 24, (2019), p. 2581.

14. Bilel Hadrich, Ismahen Akremi, Mouna Dammak, Mohamed Barkallah, Imen Fendri and Slim Abdelkafi in Hadrich et al. Lipids in Health and Disease. 17:87, (2018), pp. 2-9.

15. A. M. Lizzul, A. Lekuona-Amundarain, S. Purton and L. C. Campos in Biology. 7, (2018), pp. 1-25.

16. Y. Bazarnova, T. Kuznetsova, H. E. Boysen in International Journal of Civil Engineering and Technology. 10(9), (2018), pp. 340-350.

17. S. F Kravchenko http://www.algobiotehnologia.com/shop/?gid=98

18. Muhammad Imran Khan, Jin Hyuk Shin, and Jong Deog Kim in Microb Cell Fact. 17: 36, (2018), pp. 1-21

19. E. M. Morgunova, L. I. Nefyodov, Yu.S. Nazarova in Food Industry: Science and Technology. 4(22), (2013), pp. 65-69.

20. Meledina T.V., Davydenko S.G. Yeast Saccharomyces cerevisiae. Morphology, chemical composition, metabolism (St. Petersburg, publishing house ITMO, 2015), p. 88

21. H. O. Udeh and T. E. Kgatla in Journal of Brewing and Distilling (September 2013). 4(2), pp. 19-45
22. E.G. Kulikova, S.Yu. Efremova, N. Politaeva, Y. Smyatskaya in IOP Conference Series: Earth and Environmental Science, 288(1), (2019), 012064 doi:10.1088/1755-1315/288/1/012064

23. N. Politaeva, Y. Smyatskaya, A. Toumi and A. Oparina in Eurasian Chemico-Technological Journal, 20(3), P. 243-247

24. N. A. Politaeva, Yu. G.Bazarnova, Yu. A. Smyatskaya, T.A. Kuznetsova, E.V. Trukhina. Patent RUS. 2668162 12/06/2017.

25. Yu.G. Bazarnova., T.A. Kuznetsova, Yu. A. Smyatskaya. Patent RUS. 2695879. 29.07.2019.

26. T. A. Kuznetsova, O. B. Ivanchenko, N.S. Kalinkin in International Research Journal. 8-2(62), (2017), pp. 16-20.

27. A.S. Borgoyakova, T.A. Kuznetsova in the collection: Science Week SPbPU Materials of a scientific conference with international participation (St. Petersburg, November 13-19, 2017), pp. 8-10.

28. Elke Nevoigt in Microbiology and molecular biology reviews (Sept. 2008), p. 379-412. 